\title{
Antonio Gramsci e a crítica da cultura: intelectuais, política e classes subalternas
}

\author{
Daniela Xavier Haj Mussi \\ Universidade de São Paulo (USP)
}

Antonio Gramsci e a crítica da cultura: intelectuais, política e classes subalternas

Resumo: O artigo explora a pesquisa realizada por Gramsci nos Cadernos do Cárcere sobre a crítica da cultura, em particular a crítica literária. Mostra o desenvolvimento deste tema nos escritos da prisão a partir da reflexão sobre o lugar dos intelectuais italianos no contexto nacional do século 19. Evidencia duas interpretações desenvolvidas por Francesco De Sanctis e Benedetto Croce. Assinala a proposição original que o marxista sardo desenvolve para a crítica literária e cultura, tentando combinar a reflexão sobre os problemas do desenvolvimento de uma perspectiva popular para o problema da cultura e o elemento artístico.

Palavras-chave: Classes subalternas. Intelectuais. Crítica da cultura.

\section{Antonio Gramsci and the Criticism of Culture: Intellectuals, politics and subaltern classes}

Abstract: This article explores a study conducted by Gramsci in the Prison Notebooks about cultural criticism, in particular, literary criticism. It shows the development of this theme in the prison writings based on a reflection on the place of Italian intellectuals in their 19th century national context. It reveals two interpretations developed by Francesco De Sanctis and Benedetto Croce. It indicates the original proposal that the Marxist developed for literary criticism and culture, in an effort to apply this reflection to the problems of the development of a popular perspective of culture and art.

Keywords: Subaltern classes. Intellectuals. Cultural Critique. 


\section{Introdução}

Cultura e crítica literária tiveram lugar especial nas reflexões de Gramsci no período em que esteve preso. Longe de propor uma reflexão especializada, o marxista procurou evidenciar o lugar histórico e político da atividade crítica como um momento de transformação da própria atividade intelectual nos contextos de lutas nacionais em países europeus do século 20. No ambiente italiano, a derrota da perspectiva democrática e popular no processo de unificação nacional conferia a oportunidade de investigar em que medida a crítica literária, concebida em si mesma, não representava os contornos de uma concepção limitada e mesmo conservadora.

O presente artigo explora o processo de investigação de Gramsci sobre estes temas: a partir de seu esforço por passar em revista as contribuições filosóficas de Benedetto Croce, o retorno ao modelo elaborado pelo crítico democrático Francesco De Sanctis e a proposição por Gramsci de uma crítica cultural e literária como combinação da perspectiva popular com o mundo artístico. Mostra como Gramsci pensou a literatura e a crítica literária de um ponto de vista político-pedagógico, mas não populista. Para Gramsci, a questão literária deveria orientar a formação de novos e melhores intelectuais, ou seja, deveria significar, ao mesmo tempo, como negação da tradição livresca da vida intelectual italiana e do senso comum embutido no folclore e subalternidade cultural da vida popular. Em seguida, o artigo discute o processo de atualização das ideias de Francesco De Sanctis, levado a cabo nos Cadernos do Cárcere por meio do qual Gramsci elaborou um modelo de crítica cultural a partir da necessidade de superação das condições passivas nas quais se formara o Estado nacional italiano, esmagado em suas mais altas pretensões tanto pela afirmação de uma tradição cosmopolita e antipopular entre os intelectuais, como pelo caráter conservador e antidemocrático do Estado nascente.

\section{O primado da qualidade: o modelo de Benedetto Croce}

Em seus Cadernos do Cárcere, especialmente nos escritos que deram origem ao Caderno $10-A$ filosofia de Benedetto Croce, Gramsci discutiu as riquezas e limites do pensamento do filósofo napolitano, tendo como um de seus centros reflexivos o tema da distinção entre o intelectual profissional e não profissional. A escolha de Croce como interlocutor partia do reconhecimento de sua crítica às correntes positivistas da sociologia e psicologia, por certo diálogo promovido pelo filósofo com o pensamento marxista e pela popularidade de Croce no ambiente intelectual italiano das primeiras décadas do século 20. O "elemento filosóficometódico (unidade entre filosofia e senso comum)", sua influência sobre amplos estratos intelectuais, característica do pensamento crociano, precisava ser enfrentado (Q. 10, I, p. 1207)1.

Para Gramsci, a vitalidade do pensamento de Croce - sua eficácia em expor uma filosofia e propor um método de pensamento a ela coerente - era resultado de um legítimo esforço de renovação intelectual pelo filósofo na virada do século 19-20. Gramsci reconhecia, por exemplo, a rica influência das ideias do crítico literário risorgimentale Francesco De Sanctis no pensamento de Croce. Na opinião do marxista sardo, o filósofo se utilizara destas ideias para formular uma "dialética dos 'intelectuais' que se concebem a si mesmos como personificações das teses e antíteses e, por isso, os elaboradores da síntese". Não por acaso, observava Gramsci, esta tentativa de encontrar um lugar "especial" para os intelectuais coincidia com um processo de politização da vida intelectual, de revalorização do engajamento de historiadores, críticos e filósofos, e em particular com a conversão da "revolução passiva" em "fórmula de ação" (Q. 10, I, p. 1207).

Como parte elementar de sua trajetória de renovação intelectual, Croce absorvera as ideias marxistas difundidas no final do século 19 , segundo uma leitura que procurava evitar a redução do marxismo ao mecanicismo econômico. Disto resultava, por exemplo, a valorização crociana do marxismo como concepção não determinista da história. Para Gramsci, esta era um contribuição inegável de Croce para a renovação da vida intelectual que esbarrava, porém, na interpretação cosmopolita da história da Europa do século 19 como revolução passiva. A historiografia crociana, em sua opinião, prescindia justamente do "momento da luta, no qual a estrutura é elaborada e modificada, para assumir placidamente como história o momento da expansão cultural" (Q. 10, I, p. 1209).

Gramsci percebia na historiografia de Croce uma relação de oposição e subordinação da política (o momento da luta) pela cultura, a qual criticava por seu caráter livresco e opunha e isso a ideia de identidade entre história, cultura e política (Q.10, II, §2, p. 1242). Nesse sentido, ainda, ao recuperar o pensamento democrático de De Sanctis de maneira diferente da interpretação feita por Croce, Gramsci procurou relocalizar o lugar dos intelectuais: a "filosofia de uma época não é a filosofia de um ou de outro filósofo, de um ou de outro grupo de intelectuais (...) a filosofia de uma época não é senão a história dessa época” (Q. 10, II, §16, p. 1255). O moralismo do qual Croce acusava os intelectuais do período risorgimentale, e do qual pretendia corrigir De Sanctis numa interpretação livresca era, para Gramsci, uma forma da consciência da relação problemática entre a reforma da cultura e literatura na Itália, que aparecia em Croce tal como entre os intelectuais do século 
19, preocupados com o problema da língua, de ausência de literatura popular etc., (Q.14, §14, p. 1669). Em sua investigação sobre Croce, Gramsci percebeu que na virada do século Croce tinha certa preocupação democrática em sua atividade intelectual da qual se afastara paulatinamente, a especialmente depois da Revolução Russa de 1917, e que esta mudança tinha impacto sobre sua interpretação do pensamento de De Sanctis. "Mas não é também esta reação [de Croce] um ato construtivo de vontade? Não é um ato voluntário a conservação?", indagava Gramsci a respeito (Q.14, §14, p. 1669). Com isso, procurava mostrar que o julgamento de Croce, bem como sua filosofia, eram consequências de uma postura intelectual engajada, até certo ponto utópica, de "conservar o existente e impedir o surgimento e organização de forças novas que atrapalhariam e subverteriam o equilíbrio tradicional" caro ao filósofo (Q. 6, §86, p. 762). Estas reflexões levavam Gramsci a concluir que a filosofia de uma época, especialmente em sua eficácia em organizar a vida cultural e política, deveria ser pensada como parte de uma história dos conflitos desta época. Neste sentido, ao desprezar os momentos de luta, o pensamento de Croce o tornava semelhante ao homem de Guicciardini² ${ }^{2}$ tão criticado por De Sanctis, aquele "que assume como único método de ação política aquele no qual o progresso, o desenvolvimento histórico, resulta de uma dialética de conservação e inovação", mas nunca de ruptura (Q. 6, II, §41, p. 1325). Um método no qual a cultura possuiria valor absoluto.

Na história ético-política crociana, Gramsci notava uma tradução da fórmula guicciardiana da conservação da vida do Estado por meio da ideia do uso das "armas e religião" (Q.6, §87, p. 762-763). Assim como o Guicciardini, Croce possuía uma concepção política do Renascimento na qual "a religião é o consenso e a Igreja a sociedade civil, o aparato de hegemonia de um grupo dirigente que não possuí um aparato próprio", ou seja, "uma direção incapaz de organização cultural e intelectual própria” (Q.6, §87, p. 762-763). Gramsci oferecia um argumento diferente, animado pelo pensamento de Maquiavel, do Renascimento como momento de fratura entre ciência e vida e, ao mesmo tempo, de exigência da busca pela a ligação entre estes dois polos, entre intelectuais e povo (GERRATANA, 1952, p. 504). O que Croce via no Renascimento como exaltação da autonomia dos intelectuais, Gramsci via como crise do encapsulamento destes no interior de instituições culturais e

O conflito e a contradição, no modelo de Gramsci, passavam a ser parte necessária da atividade literária e da crítica; mais do que isso, a representação e consideração cultural do feito impediriam a cristalização das contradições: o feio passa a possuir o mesmo direito que o belo na vida cultural.segmento, aliando suas necessidades a seus direitos. econômicas em franca crise.

Gramsci (Q. 10, II, §50, p. 1341) concordava com a tentativa realizada por Croce em mostrar que entre qualidade (intelectuais) e quantidade (povo) não existia senão uma diferença de extensão, diferença por meio da qual a vida intelectual se destaca diante do senso comum, mas buscava aprofundar essa questão:

Se o nexo quantidade-qualidade é incindível se põe a questão: onde é mais útil aplicar a própria força de vontade: para desenvolver a quantidade ou a qualidade? Qual dos dois aspectos é mais controlável? Qual é mais facilmente medido? Sobre qual é possível fazer previsões, construir planos de trabalho? A resposta não parece haver dúvidas: sobre o aspecto quantitativo. Afirmar, portanto, que se quer trabalhar sobre a quantidade, que se quer desenvolver o aspecto ‘corpóreo' do real não significa que se queira descuidar da qualidade, mas significa ao contrário que se quer colocar o problema qualitativo em sua forma mais concreta e realista, ou seja, se quer desenvolver a qualidade da única maneira na qual tal desenvolvimento é controlável e mensurável.

Gramsci se valeu, portanto, da elaboração crociana que estabelecia uma relação de extensão original entre intelectuais e povo para avançar na ideia de que, ainda que existam processos de diferenciação intelectual, esta igualdade originária permite negar a primazia dos intelectuais. E avançava em sua crítica ao perceber que distinção entre filosofia e política no pensamento de Croce

implicava, também, uma especialização ou especificação dos sujeitos. A distinção das formas espirituais encontrava nos indivíduos singulares a especificidade de suas vocações. A demarcação que Croce levava a cabo entre essas formas encontrava, dessa maneira, sedes fisicamente separadas (BIANCHI, 2008, p. 101). 
Os intelectuais não poderiam ser o homem do povo; o homem povo não poderia ser filósofo. A tentativa de Croce em sustentar o desenvolvimento exclusivo e qualitativo das artes - visível em sua interpretação do Renascimento italiano - contra as grandes quantidades populacionais - em sua opinião, tema mais propriamente adequado à sociologia e psicologia positivistas -, exemplificava o profundo elitismo político e cultural do qual se servia sua moderação historiográfica, com vistas "manter intactas determinadas condições da vida social nas quais alguns são pura quantidade, outros qualidade" (Q.10, II, §50, p. 1341).

\section{O primado da vida sobre a crítica: o retorno a Francesco De Sanctis}

Em um parágrafo dos Cadernos do Cárcere intitulado "Storia delle classe subalterne" [História das classes subalternas], Gramsci (Q.3, §90, p. 373) apresentou a ideia de que a burguesia italiana não soubera unificar o povo durante o Risorgimento e que essa fora uma das causas de sua derrota e da interrupção de seu desenvolvimento como classe dirigente na Itália. Tratava-se de um egoísmo de classe que impedira uma revolução rápida e vigorosa na península no século 19 como havia sido a Revolução Francesa de 1789. Esse argumento histórico e comparado permitiu a Gramsci estabelecer um contraste da realidade italiana com o cânone de pesquisa da história europeia moderna: a burguesia francesa tomara o poder lutando contra certas forças sociais com a ajuda de outras forças; para unificar-se no Estado, essa burguesia eliminara as primeiras e obtivera o consenso ativo ou passivo das últimas. As classes subalternas francesas, neste processo, haviam sido capazes de conquistar alguma autonomia e perceber a necessidade de forjar alianças com a burguesia revolucionária buscando integrá-las, ativa ou passivamente, no novo Estado. A investigação sobre a história da formação dos Estados deveria partir de uma dupla medida: a história das classes dirigentes e dominantes (burguesia) e a história das classes dirigidas e dominadas (subalternas), medida que entrara em decadência entre os intelectuais italianos e tivera por consequência profundos enganos e dificuldades de interpretação. Do ponto de vista de uma história da cultura, os intelectuais italianos haviam sido historicamente incapazes de formular seriamente a respeito da tradição nacional. Isto se devia, em sua opinião, principalmente ao fato dos intelectuais não terem sido capazes de pensar a si mesmos, genialidades individuais, como ativamente incorporados, ou seja, integrados politicamente e socialmente nos processos nacionais. Da mesma forma, história da literatura italiana deveria ser examinada "do ponto de vista da história da cultura", na qual a explicação sobre ausência de uma literatura nacional, por exemplo, deveria ser intimamente vinculada ao estudo das "necessidades mais profundas e elementares, porque a literatura existente, salvo exceções, não é ligada à vida nacional-popular, mas aos grupos restritos que da vida nacional não são, senão, moscas varejeiras", concluía Gramsci (Q.23, §57, p. 2252).

Faltava aos intelectuais e dirigentes políticos italianos, em particular àqueles do período da unificação nacional do país no século 19 (período conhecido por Risorgimento), a compreensão de que a necessária reconstrução histórica dos aspectos da vida íntima da península deveria levar em conta a própria organização da cultura e dos grupos que a representavam, ao longo dos tempos. Seria necessária a compreensão, nas palavras de Gramsci, de que a história da cultura é mais ampla que a história literária, da literatura ou dos literatos. Seria uma investigação capaz de reconhecer a contribuição dos florescimentos da cultura popular e não apenas da cultura intelectualista. A história da cultura, como proposta por Gramsci (Q.29, §2, p. 2343), deveria levar em conta, dessa forma, a ideia de uma "gramática histórica", "que não poderia não ser comparada". Uma história que levasse em conta, portanto, o "fato linguístico" e extrapolasse seus limites em relação à língua "culta"; que considerasse, ainda, o ponto de vista "mundial" no qual as histórias nacionais, "particulares", são apenas enquadramentos. Esta gramática e este horizontes aparecem em alguns comentários nos Cadernos sobre as reflexões do intelectual italiano do Risorgimento, Ruggero Bonghi (1826-1895), ${ }^{3}$ sobre por que a literatura italiana não é popular na Itália. Para responder a esta pergunta, Gramsci partiu do caráter de documento histórico das reflexões de Bonghi, representante do dilema posto e não resolvido na Itália ao longo do século 19: a não formação de um bloco nacional e moral no país. Os intelectuais italianos, ainda que pudessem indagar a respeito dos problemas da formação de uma Itália moderna, especialmente livre do domínio clerical, mantinham-se separados da vida popular do país, compartilhavam um tipo de sentimento de "diferenciação [dos intelectuais] em um ambiente primitivo". Os ideais do pensamento liberal e democrático italiano, difundidos entre os intelectuais que compunham a ala moderada e a ala radical do processo de unificação nacional, resultavam igualmente em uma indiferença em relação à miséria das massas agrícolas italianas, e confluíam em um programa político "sem fins concretos e definidos, mas em um estado de ânimo vago e oscilante" que resultava em fórmulas políticas vazias (GRAMSCI, Q.6, §158, p. 813).

Em seus escritos carcerários, Gramsci (Q.8, §208, p. 1067) apresentou a ideia de que a relação entre política e a atividade literária, duas "superestruturas equivalentes e traduzíveis reciprocamente", já se mani- 
festava pelo menos desde a Revolução Francesa e que, por este motivo, a crítica literária se convertera em uma forma de "consciência do século 19". A crítica literária estabelecia com a arte a mesma relação que a filosofia estabelecera com a natureza, de distanciamento e aproximação, e em alguma medida, como a filosofia a crítica poderia possuir sua "história natural, uma anatomia, uma fisiologia, uma física e uma metafísica". Ou seja, a atividade crítica possuía intimidade com a fisionomia cultural do século 19, de "renovação de todos os juízos, pela modificação de todas as impressões, de elevação da cultura geral" (DE SANCTIS, 1974, p. 307). A crítica literária assumia, no século 19, lugar semelhante àquele que o pensamento jusnaturalista adquirira no contexto das monarquias do século 16-17, ou seja, um lugar fundamentalmente político. Neste sentido, pressupor a oposição entre literatura e política era como pressupor falsos antagonismos, como arbitrário versus necessário, reforma versus revolução, liberdade versus necessidade. Gramsci notava que este tipo de oposição era levado adiante pelos intelectuais liberais e democráticos na Itália do século 19 (MONDOLFO, 1942, p. 71-72), o que fortalecia os políticos e intelectuais conservadores católicos e contrários à unificação. De Sanctis (1974, p. 10-11), ao falar sobre um intelectual conservador católico, o Padre Bresciani (1798-1862), ${ }^{4}$ notara o mesmo:

A revolução, ele [Padre Bresciani] estudou pelas praças, nas vulgaridades, nos cafés, nos jornais, nas salas dos ociosos. E quem faz a revolução? (...) Nós respondemos: Uma revolução é geral, uma revolução europeia não foi feita pelas sociedades secretas, (...) [a revolução] foi feita pela consciência desperta de um povo que vocês foram forçados a fracionar, sem poder impedir o sentimento de unidade. (...) Mas essa não é vossa opinião, que pensam que a revolução foi feita pela ausência de religião, pelo desapego aos princípios (...), pela falsa liberdade.

De Sanctis desejava que "a 'literatura' se renovasse porque o povo italiano colocava esta necessidade" e, nesta medida, fazia desaparecer separação entre literatura e vida (GRAMSCI, Q.6, §44, p. 721). Intelectuais como Padre Bresciani emergiam na medida em que este processo não era levado adiante. Dessa maneira, o Gramsci (Q.14, §14, p. 1669; cf. Q.21, §1, p. 2108) identificava na atividade do crítico aquela capaz de se diferenciar da "Itália literária", dominada por polêmicas artificiais e mitologias abstratas. Entre os intelectuais democráticos do século 19 italiano, estas mitologias se materializavam na ideia de uma "Itália eterna"; entre os intelectuais liberais, na contraposição entre "Itália culta" e "Itália primitiva". Neste meio, era fundamental estabelecer um novo marco para o debate literário e crítico, um ponto de partida capaz de pensar justamente a conexão problemática entre os intelectuais e líderes da unificação nacional e o povo que estes buscaram reunir para fundar o Estado nacional italiano.

De maneira alternativa às tendências liberais e democráticas, De Sanctis aparecia para Gramsci como um ponto de referencia para um enquadramento não linear do problema da relação entre vida literária e vida política contido na ideia de uma totalidade cultural original que se fragmenta, se transforma e que volta a se reunir em momentos concretos. Na crítica literária realizada por De Sanctis em sua Storia della Letteratura Italiana [História da Literatura Italiana], ${ }^{5}$ forma e conteúdo literário, integrados em determinada obra literária, poderiam se encontrar dispersos no momento seguinte e encontrar um novo ponto de fusão, sobre outra forma representativa, em momento histórico posterior (WELLEK, 1967, p. 111). Isso significa que o conteúdo cultural não se encontrava aprisionado pela forma literária, mas em relação de constante tensão com a mesma, transformandoa e sendo transformado por ela. Da mesma forma deveria ser pensada a relação entre intelectuais e povo.

Em reação ao diálogo com essa interpretação da crítica literária, Gramsci (Q.3, §151, p. 405) propôs a literatura como fenômeno conectivo e dispersivo entre o universo artístico e popular, e isso o levou a realizar uma nova pesquisa sobre por que determinada literatura "é lida, é popular, é pesquisada". Diferente dos argumentos tradicionais e a partir de uma forma de pensar não estreitamente literária, a pesquisa de Gramsci propôs um novo foco, democrático, orientado para compreender o público como alternativa à crítica artística que se fixava apenas na beleza da cultura e literatura. A leitura que fazia do papel da crítica literária assumia contornos diferentes do modelo sistemático da filosofia de Croce: Gramsci resgatava na crítica literária de De Sanctis a ideia do artista como alguém que participa da história em geral, e não apenas no nível da fantasia e da imaginação. Afinal, se Croce se limitara à ideia "é artista, então é homem", De Sanctis teria antes afirmado "que não basta ser artista, é preciso ser homem" (GERRATANA, 1952, p. 502).

A produção artística é inconsciente, mas não no sentido de se opor à racionalidade, ao conteúdo ou às ciências do mundo, e sim na medida em que absorve as ideias e as transforma numa organicidade própria, em ato de vida artisticamente real (GUGLIELMI, 1976). A consciência, por sua vez, que falta ao artista deveria ser justamente o que anima uma segunda atividade, a da crítica. Nesse sentido, De Sanctis conferia um sentido unitário profundo ao trabalho do artista e do crítico, sentido este que só se tornaria possível em função daquilo que é complexo na sociedade e na história moderna. 


\section{Popular e artístico: a crítica literária de Gramsci}

Em sua crítica, De Sanctis discutira com frequência sobre a obra de arte como um mundo especial e suas personagens em termos do conflito entre o ideal e o real, o característico e o geral, a imagem e o fantasma. Esse mundo especial nunca era, porém, resultado de uma separação definitiva entre os termos (WELLEK, 1967). Importava mostrar a tensão entre forma e conteúdo, um estado de incompletude do qual origina a da atividade crítica. Sob essa concepção, a crítica passava a ser concebida não mais como técnica ou filosofia da arte, forma pronta e acabada de classificação estética. Neste sentido, o problema da ausência de uma literatura popular italiana ganhava contornos inteiramente novos. Foi esta novidade que Gramsci (Q.14, §72, p. 1739) valorizou no modelo desanctiano, a atenção dada para a relação "entre intelectuais e povo" no tratamento dos problemas culturais. A história e crítica literária eram compreendidas, aqui, "como parte e aspecto de uma mais vasta história da cultura". Mais ampla do que uma história literária contada em si mesma, uma história da cultura compreenderia os fenômenos artísticos "aproximados da atividade política", ou seja, como parte de uma "política cultural". O "retorno" a De Sanctis 6 implicava a construção de parâmetros para uma atividade de crítica literária concebida como crítica da cultura e, assim, como parte de uma história da cultura e da política. Para tal, uma temática fundamental ao pensamento de De Sanctis foi recuperada por Gramsci: a da defesa da necessidade de projetar uma nova sincronia entre ciência e vida, a humanização da atividade intelectual e a revalorização da consciência cotidiana, o reencontro entre pensamento e vida, entre liberdade e limite ${ }^{7}$. Gramsci converteu a elaboração desanctisiana sobre a relação entre ciência e vida no tema da superação da separação entre dirigentes e dirigidos, mantida tanto pelo sistema de pensamento positivista como pelo neodealista. Para tal conversão, Gramsci aproveitou a ideia de Croce da identidade fundamental entre intelectuais e povo em algum nível. Esta ideia era o que permitia, ainda que potencialmente, o conhecimento e a busca recíproca de conteúdo entre os termos.

"Todos os homens são filósofos", "todos os homens são intelectuais, melhor dizendo, mas nem todos os homens possuem na sociedade a função de intelectuais". A partir do desenvolvimento da diferença de extensão entre filósofos e povo, Gramsci (Q.8, §220, p. 1080; Q.11, §, p. 1383) apresentou a necessidade de uma teoria e atividade crítica que considerassem a existência de material anterior e que se torna literatura, sendo que qualquer material poderia tornar-se literário: "não se trata de introduzir ex-novo uma ciência na vida individual de 'todos', mas de inovar e tornar 'crítica' uma atividade já existente". Nesta atividade crítica, inclusive, o que é considerado feio, contraditório e conflituoso dentro dos padrões da alta cultura não só poderia ser assunto para a literatura, como seria preferível, pois o "belo não é senão ele mesmo, enquanto o feio é ele mesmo e o seu contrário" (DE SANCTIS, 1973, p. 225). O conflito e a contradição, no modelo de Gramsci, passavam a ser parte necessária da atividade literária e da crítica; mais do que isso, a representação e consideração cultural do feito impediriam a cristalização das contradições: o feio passa a possuir o mesmo direito que o belo na vida cultural.

Em seus escritos carcerários, Gramsci (Q.3, §14, p. 299-300) retira do campo estritamente literário os critérios que definiriam uma narrativa a respeito das classes subalternas:

Uma história das classes subalternas é necessariamente desregrada e episódica: existe na atividade dessas classes uma tendência à unificação, ainda que em plano provisório, mas essa é a parte menos aparente e que se mostra apenas quando a vitória é alcançada. As classes subalternas sofrem a iniciativa da classe dominante, mesmo quando se rebelam; estão em estado de defesa alarmada. De qualquer forma, a monografia é a forma mais apta dessa história, que exige acúmulo muito grande de materiais parciais.

Uma história das classes subalternas seria, necessariamente, uma história de si mesma e do seu contrário, ou seja, uma narrativa do belo e do feio, sobre a desagregação e o caráter episódico da vida dessas classes e do esforço por se unificarem em um momento mais alto, como nova classe dirigente e dominante. Posteriormente, Gramsci (Q.25, §5, p. 2287-2288) refinou essa observação metodológica ao reelaborar o parágrafo já citado do Caderno 3, História das classes subalternas, em um novo texto, agora no Caderno 25. A nova versão trazia a ideia de que:

a unidade histórica das classes dirigentes se dá no Estado e a história deste é essencialmente a história dos Estados e dos grupos de Estados. (...) A unidade histórica fundamental, pela sua concretude, é resultado das relações orgânicas entre Estado, ou sociedade política, e 'sociedade civil'. As classes subalternas, por definição, não estão unificadas e não podem se unificar enquanto não se tornarem 'Estado': a sua história, portanto, se confunde com a da sociedade civil, é uma função 'desregrada' e descontínua da história da sociedade civil e, por isso, da história dos Estados ou grupos de Estados. 
As formas de narrar a experiência das classes subalternas e das classes dirigentes, do povo e dos intelectuais, do feio e do belo, encontravam sua distinção na relação dessas classes com o Estado, ou seja, na política. Esta relação explicaria as origens do desregramento e da descontinuidade da sua história dos subalternos. O exemplo gramsciano (Q.25, §5, p. 2289) era o da própria realidade italiana no contexto de sua unificação nacional. Para compreendê-la:

muitos cânones de pesquisa histórica podem ser construídos a partir do exame das relações das forças inovadoras italianas que orientaram o Risorgimento nacional: estas forças tomaram o poder, foram unificadas no Estado moderno italiano, lutando contra forças determinadas e ajudadas por forças auxiliares ou aliadas; para se tornar Estado deveriam subordinar ou eliminar as primeiras e obter o consenso ativo ou passivo das segundas. O estudo do desenvolvimento dessas forças inovadoras, de grupos subalternos a grupos dirigentes e dominantes deve, portanto, pesquisar e identificar as fases através das quais elas adquiriram autonomia no confronto com os inimigos e a adesão dos grupos que as ajudaram passivamente ou ativamente, na medida em que todo esse processo foi necessário historicamente para que se unificassem no Estado.

Gramsci (Q.23, §57, p. 2251) partia da constatação da pouca popularidade da literatura italiana na Itália para realizar um juízo histórico sobre a cultura da península e sua posição no continente europeu. Na Itália, "o passado não vive no presente, não é elemento essencial do presente, ou seja, na história da cultura nacional não existe continuidade e unidade". A afirmação de uma continuidade e unidade, do encontro da nação italiana com uma vida literária renovada e influente, nesse caso, "era apenas uma afirmação retórica, com valor de mera propaganda sugestiva, um ato prático, que tende a criar artificialmente aquilo que não existe, não é uma realidade em ato". Se o passado não se convertia em elemento de vida, isso significava apenas que o sentimento nacional era recente, "em vias de formação", e isso reafirmava o caráter tradicionalmente não nacional, cosmopolita, da intelectualidade e vida cultural italiana. O marxista percebia que o conflito da separação entre intelectuais e povo se mantinha nas primeiras décadas do século 20 , assim como a subordinação da Itália à hegemonia intelectual e moral estrangeira. Mais do que isso, sob o fascismo, quanto mais "repressiva e nacionalista" se tornava sua realidade política e econômica, menos suas classes dirigentes e seus intelectuais eram capazes de perceber que se encontravam sob os efeitos de uma hegemonia cultural que eram incapazes de reverter:

Se for verdade que cada século ou fração de século possui sua literatura, não é sempre verdadeiro que esta literatura seja produzida na mesma comunidade nacional. Cada povo possui sua literatura, mas essa pode vir de outro povo, isto é, o povo na palavra pode ser subordinado à hegemonia intelectual e moral de outros povos. É próprio este o paradoxo mais estridente para muitas tendências monopolistas de caráter nacionalista e repressivo: que enquanto constroem para si planos grandiosos de hegemonia, não se percebem como objeto de hegemonia estrangeira; assim como, enquanto fazem planos imperialistas, na verdade são objetos de outros imperialismos, etc. No entanto, não se sabe se o centro político dirigente não compreenda bem a situação de fato e procure superá-la: é certo, porém, que os literatos, neste caso, não ajudam o centro dirigente político nesse esforço, e seus cérebros vazios se obstinam na exaltação nacionalista justamente para não sentir o peso da hegemonia da qual dependem e sob a qual são oprimidos (GRAMSCI, Q.23, §57, p. 2253).

Para o caso da literatura, o antídoto para a dependência estava na recuperação do momento artístico através do desenvolvimento da crítica militante, não friamente estética, própria de um período de lutas culturais pela unidade italiana, de contrastes entre concepções de mundo antagônicas. A crítica artística deveria ser coordenada pela luta cultural e, por isso, Gramsci pensou na figura do crítico literário como homem de partido, cujas sólidas convicções morais e políticas orienta, a totalidade de sua reflexão intelectual. Nesse sentido, De Sanctis e Croce estavam em lados opostos: se, em De Sanctis, existia a paixão e o fervor das lutas pela unidade nacional, isso foi substituído em Croce pela serenidade superior de quem dita a literatura, posição constantemente ameaçada pelas crises do caráter politicamente regressivo ao qual esse triunfalismo cultural foi aos poucos sendo combinado.

Era uma consciência, entretanto, para a qual a forma era um "a priori da técnica", uma mecânica literária (GUGLIELMI, 1976, p. 41-42). Essa era a dimensão histórica, ou situacional, valorizada e traduzida para o século 19 por De Sanctis, exigindo do Risorgimento que assumisse uma vitalidade condizente com a superação daquela tradição cosmopolita do Renascimento: "estamos em tempos de transições e de transformações" dizia De Sanctis (1998, p. 89-107) para a Itália de 1877, e "tempos de transições e de novas elaborações surgem quando o real e o ideal estão separados, ou melhor, se contradizem".

Não caberia ao universo da crítica dissolver o universo poético, e vice-versa, mas construir com este uma unidade transformada em razão, em consciência de si própria. A crítica, nesse sentido, era também uma 
concepção poética, vista de outro ângulo: a criação repensada ou refletida. A fusão da crítica com a poesia não era, senão, o realismo evocado por De Sanctis (1998, p. 122): “O mérito do realismo é dar ao homem um exato conhecimento de suas origens, de seu ambiente, de suas forças, de seus meios e da sua missão nesta terra. $\mathrm{O}$ homem deve se acostumar a não desejar senão aquilo que pode conseguir, a não colocar sua mira onde não pode alcançar, a estudar suas forças e os seus meios, e proporcionar os seus fins".

Para Gramsci (Q.21, §1, p. 2109), o argumento sobre o "moralismo na arte" usado por Croce, como crítica ao "conteúdo externo à arte" e separação entre história da cultura e história da literatura, era incapaz de perceber que a literatura é sempre ligada ao desenvolvimento histórico-político de determinada cultura ou civilização e que, ao lutar para reformar a cultura, o "conteúdo" da arte se transforma, ou seja, se trabalha para "criar uma nova arte, não a partir de fora (como arte didática, de teses, moralista), mas a partir do interior, por que o homem todo é modificado quando são modificados os seus sentimentos, as suas concepções e relações das quais o homem é expressão necessária". A relação de unidade e distinção entre intelectuais e povo, ciência e vida, na filosofia de Croce era assumida como um fato dado e não poderia ser pensada como um problema ou como um programa de ação (GERRATANA, 1952, p. 503). A vida intelectual para Gramsci, por outro lado, não era o resultado do pensamento deste ou daquele indivíduo, mas uma produção ativa, contínua do cérebro coletivo que se chama povo, produção impregnada de todos os elementos forças e interesses da vida, neste cérebro ela deveria procurar sua legitimidade, a sua base de operação. Nesse caso, a relação de unidade/distinção entre intelectuais e povo era vista por Gramsci (Q.10, §17, p. 1255) não como fato, mas como um problema histórico:

\begin{abstract}
A filosofia de uma época histórica não é a filosofia de um ou de outro filósofo, de um ou de outro grupo de intelectuais, de uma ou de outra parte das massas populares: é a combinação de todos esses elementos, que culmina em uma determinada direção, no qual o seu culminar se torna norma de ação coletiva, isto é, se torna história. A filosofia de uma época história não é senão a 'história' dessa mesma época (...) história e filosofia são incindíveis neste sentido, formam um 'bloco'.
\end{abstract}

A literatura italiana era, para Gramsci (Q.10, §17, p. 1255), parte intrínseca de uma história italiana, "massa de variações que o grupo dirigente precisa determinar da realidade precedente", com a qual estabelecia uma relação dialética. O pensamento de De Sanctis sob a interpretação gramsciana era aquele que expunha uma relação entre ideal e real, espontaneidade e consciência, qualidade e quantidade, para afirmar a necessidade da fusão entre essas duas dimensões da vida intelectual. Essa era natureza da atividade de tradução entre ciência e vida, e também entre crítica artística e crítica política.

\title{
Considerações finais
}

Gramsci buscou nas ideias de Croce e De Sanctis o argumento para a crítica do cosmopolitismo da cultura italiana, da literatura como atividade necessária e irreversivelmente separada da vida popular. Contra esta separação, defendeu uma história da cultura italiana como, ao mesmo tempo, artística e popular, dominante e subalterna. Nos escritos carcerários sobre crítica literária, Gramsci apresentou seu modelo: a crítica cultural e artística concebida como diferente de uma descrição do que a cultura ou arte representam socialmente ou, ainda, das características de determinado contexto histórico-social. Se tal descrição poderia ser útil no campo da luta dos costumes, poderia facilmente estagnar os conceitos da crítica, bloqueando o pensamento sobre a luta cultural. Em uma carta do cárcere de março de 1930, Gramsci (LC, p. 330) compartilhou seu modelo de crítica: "É preciso, a minha opinião, ser sempre muito prático e concreto, não sonhar de olhos abertos, mas colocar-se fins discretos, alcançáveis e pensá-los nas condições em que podem ser realizados; é preciso, então, possuir uma perfeita consciência dos próprios limites, se se quer alargá-los aprofundá-los”.

A crítica literária deveria ser, nesse caso, parte de uma crítica concreta do presente, a definição de um limite do ideal, ou seja, um programa de ação profundamente crítico das limitações das classes subalternas. A crítica literária que Gramsci desenvolveu era, portanto, parte da reforma intelectual e moral do povo italiano, conduzida de baixo. Essa crítica deveria apontar, sempre, para a formação de novas camadas intelectuais, críticas de sua realidade e criativas para pensar e realizar uma cultura nova.

\section{Referências}

BIANCHI, A. O laboratório de Gramsci: filosofia, história e política. São Paulo: Alameda, 2008.

DE SANCTIS, F. La democrazia ideale e reale. Napoli: Alfredo Guida, 1998. 
Storia della letteratura italiana. Torino: UTET, 1973.

Saggi. Torino: UTET, 1974.

Opere. Milano-Napoli: Ricardo Ricciardi, 1961.

GERRATANA, V. De Sanctis-Croce o De Sanctis-Gramsci? (Appunti per una polemica). Società, p. 497-512, 1952.

GRAMSCI, A. Lettere dal Carcere. Torino: G. Einaudi, 1973.

Quaderni del Carcere. Torino: G. Einaudi, 1975, 4v.

GUGLIELMI, G. Da De Sanctis a Gramsci: Il linguaggio della critica. Bologna: Il Mulino, 1976.

MAZZONI, G. Storia letteraria d'Italia. Milano: Dr. Francesco Vallardi, 1949. v.9 [L'ottocento].

MONDOLFO, R. La filosofía política de Italia en el siglo XIX. Buenos Aires: Ediciones Imán, 1942.

SAPEGNO, N. Ritrato di Manzoni. Roma-Bari: Laterza, 1992.

WELLEK, R. História da Crítica Moderna: 1750-1950. Tradução: Lívio Xavier. São Paulo: Herder, EdUSP, 1967.

\section{Notas}

1 Para efeito de simplificação e adequação ao padrão internacional especializado, os Quaderni del Carcere [Cadernos do Cárcere] estão aqui citados da seguinte forma: Q. (para o número do caderno), § ou numeração romana (para o número do parágrafo quando houver), ep. (para o número da página). A edição de referênciaé aquela curada por Valentino Gerratana (Gramsci, 1975). As Lettere dal Carcere [Cartas do Cárcere], por sua vez, estão citadas no formato LC, p. (para o número da página) a partir da edição Gramsci (1973).

2 Em oposição ao homem de Maquiavel. A reconstrução do lugar de Nicolau Maquiavel na cultura nacional da península por De Sanctis foi levada a cabo a partir da comparação com o diplomata e historiador Francesco Guicciardini (1483-1540), diplomata no período do Renascimento e autor, entre outras, da monumental Storia d'Italia. No momento em que De Sanctis escrevia, a principal motivação do retorno a Guicciardini era reagira à valorização que era feita de suas ideias em detrimento de Maquiavel, como ciência em detrimento da arte da política. De Sanctis procurou, justamente, revelar a aproximação inevitável destas duas esferas e, consequentemente, o caráter débil de Guicciardini.

3 Em 1855, Bonghi escreveu algumas cartas críticas sobre o tema de Perchè la letteratura italiana non sia popolare in Italia [Por que a literatura italiana não é popular na Itália]. Publicadas em 1856 na revista Spettatore, as cartas apresentavam o problema literário da península através da questão sobre a ausência de difusão da literatura nacional na Itália que se unificava. Mais tarde, ao se deparar com a Storia della letteratura italiana de De Sanctis, Bonghi viu suas preocupações desenvolvidas por aquele que considerou "o primeiro crítico italiano, pela virtude de saber sentir e expressar a vida de uma ideia e de uma situação poética, conseguindo refazer dentro de si e ensinar aos outros o caminho da mente e da alma de um poeta" (MAZZONI, 1949, p. 1132). Em sua Storia, De Sanctis conseguira "ilustrar um tema singular em qualquer lugar nas suas relações com uma situação cultural e política e colocar o fato artístico em uma linha evolutiva mais ou menos explícita de acontecimentos organicamente ordenados" (SAPEGNO, 1992,p. 185).

4 Em uma carta de sete de abril de 1930, Gramsci (LC, p. 335-336) escreveu sobre o que chamou "brescianismo": "uma tradição [católico-literária] essencialmente sectária”, para a qual "todos os patriotas eram canalhas, vilões, assassinos etc., enquanto os defensores do trono e do altar, como então se dizia, eram todos anjos na Terra com algum milagre para mostrar". Nos Cadernos do Cárcere, a discussão sobre o "brescianismo" como corrente cultural italiana ganhou vários parágrafos, especialmente no Caderno 21.

5 Livro publicado em 1871, obra prima de De Sanctis, no qual traçou um esboço de uma crítica da tradição literária italiana em uma linha histórica que se orientava pela relação entre a atividade artística e a vida nacional da península, de Dante Alighieri, Francesco Petrarca, Giovanni Boccaccio, Nicolau Maquiavel e Giambattista Vico, até o século 19 de Giacomo Leopardi e Alessandro Manzoni (DESANCTIS, 1973).

6 Foi com esse objetivo que Gramsci (Q.23, §8, p. 2198) se referiu a um conhecido discurso de abertura do ano escolar 1872-1873 da Universidade de Nápoles, redigido e proferido por De Sanctis. O discurso intitulado La Scienza e la Vita [A ciência e a vida] fora escrito no tempo de adesão majoritária e acrítica dos intelectuais italianos ao positivismo, e se posicionava frontalmente contra o doutrinarismo e contra a deformação intelectualista da ciência, então profundamente separada da vida (DE SANCTIS, 1961). O realismo desanctisiano se pretendia, na verdade, um antídoto contra os tipos intelectuais dados “à fraseologia e à pompa, educados naArcádia e na retórica"(WELLEK, 1967,p. 111).

7 Para De Sanctis (1961,p. 1063), a "ciênciaé a vida que se reflete no cérebro, é o produto da mesma matéria; e se a vidaéfraca, a ciência éfraca".

\section{Daniela Xavier Haj Mussi}

danixhm@gmail.com

Pós-doutoranda em Ciência Política

Universidade de São Paulo 


\section{USP}

Av. Professor Luciano Gualberto - Cidade Universitária São Paulo - São Paulo - Brasil

CEP: 05508-900 